\title{
Creating a Knowledge Translation Comic Book to Improve the Nutritional Health of Queer Men
}

\section{Phillip Joya PhD(c), PDt, Stephanie Gauvin, Matthew Lee, Matthew Numer}

a Dalhousie University

The project aimed to improve the health for GBTQ men by disrupting dominant body ideals through comic art. A comic book based on evidence-based literature and personal experiences from the GBTQ community was created. It is recommended that dietitians use arts-based approaches, such as comics, as knowledge translation strategies to address nutrition-related health concerns for marginalized communities.
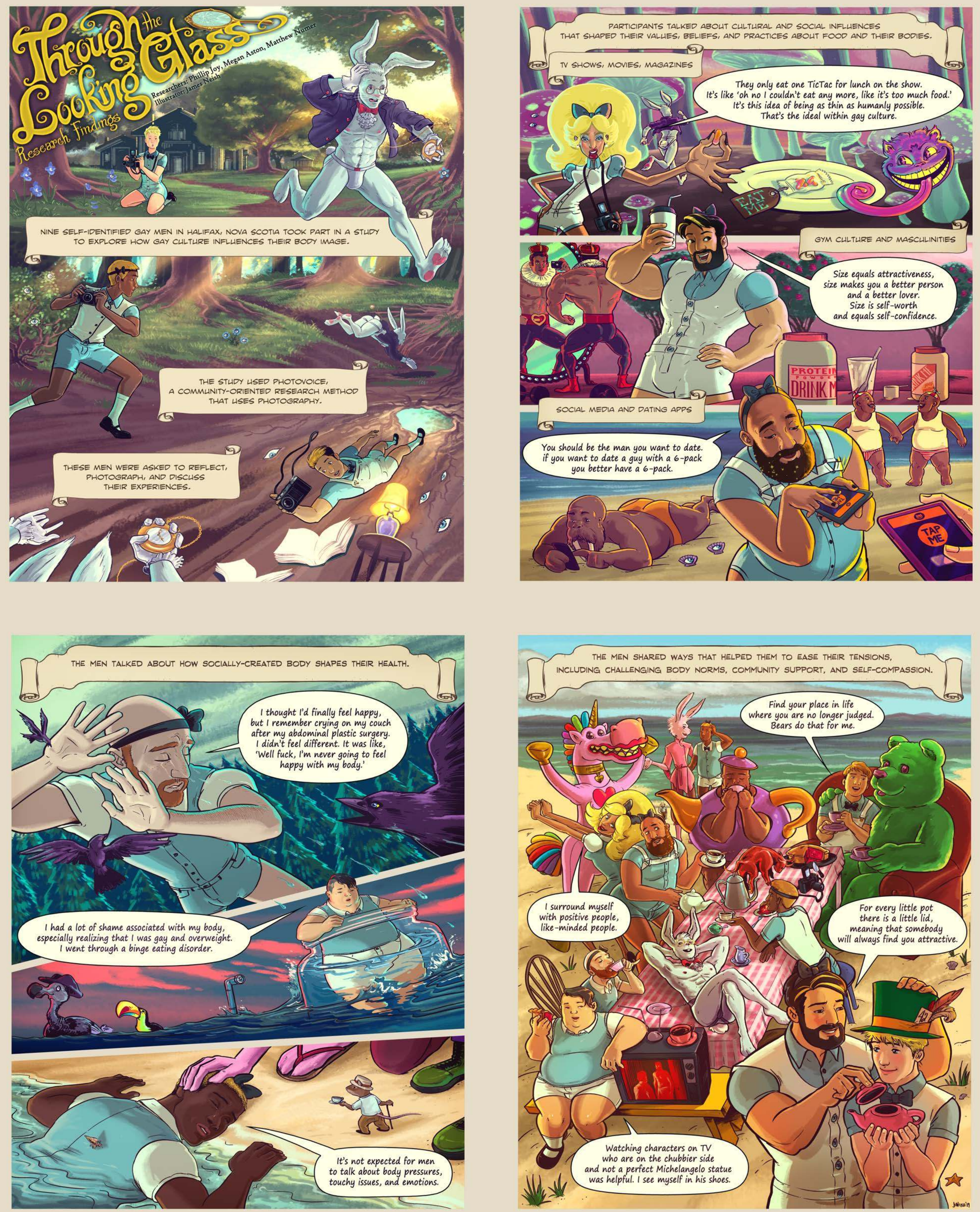